\title{
Intrapulmonary Bronchus
}

National Cancer Institute

\section{Source}

National Cancer Institute. Intrapulmonary Bronchus. NCI Thesaurus. Code C12930.

A bronchial branch that is located within the lung tissue. 